Correction

\title{
Correction: Klingler, M., et al. Cholecystokinin-2 Receptor Targeting with Novel C-terminally Stabilized HYNIC-Minigastrin Analogs Radiolabeled with Technetium-99m. Pharmaceuticals 2019, 12, 13
}

\author{
Maximilian Klingler ${ }^{\circledR}$, Christine Rangger ${ }^{\circledR}$, Dominik Summer ${ }^{\circledR}$, Piriya Kaeopookum ${ }^{\circledR}$, \\ Clemens Decristoforo and Elisabeth von Guggenberg * $*$ \\ Department of Nuclear Medicine, Medical University of Innsbruck, Anichstrasse 35, A-6020 Innsbruck, Austria; \\ maximilian.klingler@i-med.ac.at (M.K.); christine.rangger@i-med.ac.at (C.R.); \\ summer.dominik@gmail.com (D.S.); piriya.kaeopookum@student.i-med.ac.at (P.K.); \\ clemens.decristoforo@i-med.ac.at (C.D.) \\ * Correspondence: elisabeth.von-guggenberg@i-med.ac.at; Tel.: +43-512-504-80960
}

Received: 11 June 2019; Accepted: 12 June 2019; Published: 13 June 2019

check for updates

In our paper [1], an error unfortunately occurred in Figure 1. We therefore would like to provide the readers with the corrected figure and apologize for this inconvenience.
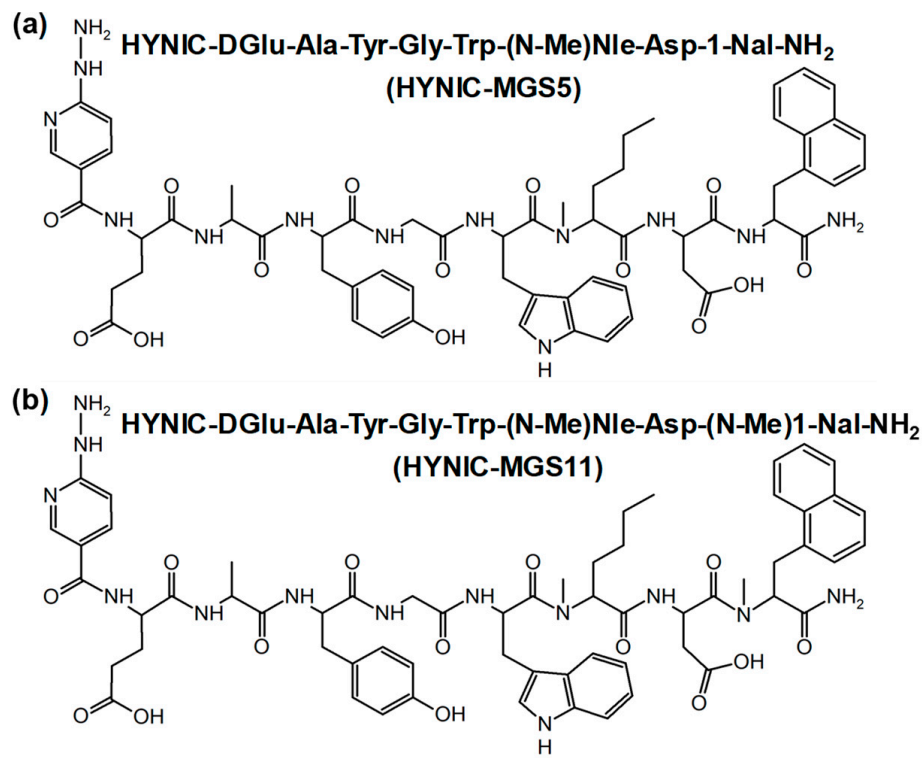

Figure 1. Amino acid sequence and chemical structure of (a) HYNIC-MGS5 and (b) HYNIC-MGS11.

\section{Reference}

1. Klingler, M.; Rangger, C.; Summer, D.; Kaeopookum, P.; Decristoforo, C.; von Guggenberg, E. Cholecystokinin-2 Receptor targeting with novel C-terminally stabilized HYNIC-Minigastrin Analogs radiolabeled with Technetium-99m. Pharmaceuticals 2019, 12, 13. [CrossRef] [PubMed]

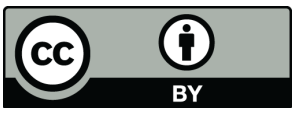

(C) 2019 by the authors. Licensee MDPI, Basel, Switzerland. This article is an open access article distributed under the terms and conditions of the Creative Commons Attribution (CC BY) license (http://creativecommons.org/licenses/by/4.0/). 